Universidade Tecnológica Federal do Paraná - UTFPR

Campus Ponta Grossa - Paraná - Brasil

ISSN: 1981-3686/ v. 08, n. 01: p. 1262-1273, 2014

D.O.I.: $10.3895 / \mathrm{S} 1981-36862014000100011$
Revista Brasileira de Tecnologia

Agroindustrial

\title{
CARACTERIZAÇÃO FÍSICO-QUÍMICA, FUNCIONAL E NUTRICIONAL DE DUAS CULTIVARES BRASILEIRAS DE ARROZ
}

\section{PHYSICOCHEMICAL, FUNCTIONAL AND NUTRITIONAL CHARACTERIZATION OF TWO RICE BRAZILIAN CULTIVARS}

\footnotetext{
Luís Fernando Polesi ${ }^{1}$; Dâmaris Carvalho Lima ${ }^{2}$; Pyera Grassi Morais ${ }^{2}$; Isabela Cristina Freitas Romo²; Silene Bruder Silveira Sarmento ${ }^{2}$; Solange Guidolin Canniatti-Brazaca ${ }^{2}$

${ }^{1}$ Universidade de São Paulo, Centro de Energia Nuclear na Agricultura - USP/CENA - Piracicaba - Brasil Ifpolesi@yahoo.com.br

${ }^{2}$ Universidade de São Paulo, Escola Superior de Agricultura Luiz de Queiroz - USP/ESALQ - Piracicaba Brasil sgcbraza@usp.br
}

\begin{abstract}
Resumo
O objetivo deste trabalho foi realizar a caracterização físico-química, funcional e nutricional de duas cultivares brasileiras de arroz. O arroz da cultivar IAC 202 apresentou maior temperatura de gelatinização, absorção de água, volume de expansão, perda de sólidos, pegajosidade e amido lentamente digerível. O arroz da cultivar IRGA 417 apresentou maior teor de proteínas, lipídeos, amilose aparente, viscosidade em RVA, dureza, amido rapidamente digerivel e amido resistente. O arroz IRGA 417 apresentou características de textura mais apreciada pelos brasileiros, com grão cozido mais firme e menos pegajoso. Além disso, apresentou vantagem nutricional sobre o IAC 202 pelo maior teor de proteínas e amido resistente.
\end{abstract}

Palavras-chave: Oryza sativa, composição, propriedades de cocção, digestibilidade do amido, textura.

\section{Introdução}

O arroz (Oryza sativa L.) é um dos cereais mais produzidos e consumidos no mundo, caracterizando-se como principal alimento para mais da metade da população mundial (WALTER et al., 2008). No Brasil, o arroz desempenha papel importante como componente da dieta básica, sendo o alimento mais consumido depois do feijão, com média de consumo diário per capita de 160,3 g/dia (IBGE, 2011). Este cereal é consumido de forma ampla em todos os estratos sociais e faixas etárias, fazendo parte da cultura e tradição brasileira (FERREIRA et al., 2005).

O estado do Rio Grande do Sul é o maior produtor de arroz do país, responsável por $64 \%$ da produção na safra 2011/2012. A produção brasileira de arroz para a safra 2010/2011 foi estimada em de 13,6 milhões de toneladas, sendo a safra atual inferior em 14\% à obtida em 2010/2011 (CONAB, 2012).

$\mathrm{O}$ arroz se constitui como importante fonte de energia na alimentação humana, devido à alta concentração de amido, além de fornecer proteínas, vitaminas e minerais (WALTER et al., 
2008). A proteína do arroz é de boa qualidade porque contêm os oito aminoácidos essenciais ao homem. O valor nutritivo do arroz beneficiado polido está muito relacionado ao seu teor proteico (CASTRO et al., 1999).

O amido, maior componente do arroz, é um polissacarídeo composto por duas macromoléculas que são a amilose e a amilopectina. A amilose é essencialmente linear formada por moléculas de glicose unidas por ligações glicosídicas $\alpha-1,4$, com menos de $0,1 \%$ de ramificação (ligações $\alpha-1,6)$. A amilopectina é o componente ramificado do amido, formada por moléculas de glicose unidas em $\alpha-1,4$ e $\alpha-1,6$, sendo esta última responsável pela ramificação da molécula (BELLO-PÉREZ et al., 2006). O conteúdo de amilose presente no arroz é de extrema importância para as características finais do produto cozido (PERDON et al., 1999).

A digestibilidade do amido está relacionada com a sua velocidade de digestão in vitro, podendo ser classificado em amido rapidamente digerível (ARD), quando converte-se em glicose em 20 minutos; amido lentamente digerível (ALD), quando converte-se em glicose em 120 minutos; e amido resistente (AR), quando resiste à ação das enzimas digestivas após 120 minutos (ENGLYST et al., 1992). O ARD é uma fração do amido que causa um súbito aumento no nível de glicose do sangue após a ingestão, o ALD é a fração do amido que é digerida completamente no intestino delgado, promovendo baixa taxa de elevação de glicose sanguínea comparado ao ARD, e o AR é a fração do amido que não é digerida no intestino delgado pela ação das enzimas digestivas, mas é fermentada no intestino grosso pela ação da microbiota intestinal (CHUNG et al., 2009).

Os benefícios do AR na saúde são reportados como prevenção do câncer de cólon, prevenção do efeito hiperglicêmico, substrato para o crescimento de microrganismos probióticos, redução da formação de cálculo biliar, efeito hipocolesterolêmico, inibição do acúmulo de gorduras e aumento da absorção de minerais (SAJILATA et al., 2006). Os potenciais benefícios à saúde do ALD estão ligados ao metabolismo estável da glicose, controle do diabetes, desempenho mental e saciedade (LEHMANN e ROBIN, 2007).

O objetivo deste trabalho foi caracterizar físico-química, funcional e nutricionalmente duas cultivares brasileiras de arroz.

\section{Material e Métodos}

Foram utilizadas duas cultivares de arroz, a IAC 202, adquirida junto ao Instituto Agronômico de Campinas (IAC) e a IRGA 417, cedida pelo Instituto Rio Grandense do Arroz (IRGA). Cada uma das cultivares foi dividida em 3 lotes de 500 g cada um em frascos de vidro e armazenados em temperatura ambiente. Foram moídos $200 \mathrm{~g}$ de cada lote em moinho (STAR FT51, Fortinox), peneirado $(250 \mu \mathrm{m})$ e armazenado em frascos de vidro em temperatura ambiente, para a realização da composição centesimal, amilose e propriedades de pasta. 


\section{Análises no arroz cru}

A composição centesimal dos grãos de arroz foi avaliada nas amostras moídas. Os teores de umidade, cinzas, proteínas, lipídeos e fibra alimentar foram avaliados segundo os métodos descritos pela AOAC (2006). O teor de carboidratos disponíveis foi estimado por diferença.

A avaliação de cor foi realizada nos grãos de arroz utilizando-se colorímetro Minolta, Modelo Chroma Meter CR-400, segundo o sistema proposto pela Comission Internacionale de L'Eclaraige (CIE). Os resultados foram expressos na escala CIELCh, onde a componente axial L é conhecida como luminosidade e se estende de 0 (preto) a 100 (branco), o croma (C), que varia na direção radial e representa a pureza de uma cor em relação ao cinza e o ângulo de tom ou "Hue" $\left(0^{\circ}\right.$ $\leq \mathrm{h}^{*} \leq 360^{\circ}$ ), que varia na direção angular e representa as diferentes cores existentes.

O teor de amilose aparente foi determinado na farinha de arroz de acordo com a metodologia de Martínez e Cuevas (1989), com adaptações de acordo com Zavareze et al. (2009).

O valor de espalhamento alcalino foi determinado segundo Little et al. (1958). Foram colocados 6 grãos crus de arroz em placa de Petri (60x15mm) e adicionado $10 \mathrm{~mL}$ de hidróxido de potássio $(\mathrm{KOH})$ 1,7\%. As placas foram tampadas e deixadas em repouso por 23 horas. Avaliou-se a extensão do espalhamento dos grãos utilizando-se a seguinte escala numérica: 1 - grão não afetado; 2 - grão expandido; 3 - grão expandido, com colarinho estreito e incompleto; 4 - grão expandido, com colarinho largo e completo; 5 - grão dividido ou segmentado, com colarinho largo e completo; 6 - grão disperso e fundido com colarinho; e 7 - grão completamente disperso e misturado.

As propriedades de pasta foram avaliadas na farinha de arroz em aparelho Rapid Visco Analyser (RVA-S4A, Newport Scientific), de acordo com o método 61-02 da AACC (2000).

\section{Análises de cocção}

A determinação do tempo mínimo de cocção (TMC), absorção de água (AA), perda de sólidos (PS) e volume de expansão (VE) do arroz foram realizados segundo a metodologia descrita por Bassinello et al. (2004) e Cui et al. (2010) com modificações. Para o TMC foram adicionados 4 g de arroz em $135 \mathrm{~mL}$ de água destilada fervente, marcando-se o tempo para cocção. Após dez minutos foram retirados alguns grãos de arroz, colocados sobre uma placa de vidro e pressionados firmemente contra outra placa. O TMC foi determinado quando os grãos se tornavam totalmente transparentes. Para a AA e PS foi pesado $1 \mathrm{~g}$ de arroz e adicionado $15 \mathrm{~mL}$ de água destilada em tubo de ensaio vedado, o tubo foi levado em banho de água fervente por $25 \mathrm{~min}$. $\mathrm{O}$ arroz foi drenado por 10 min em placa de Petri previamente tarada e pesado. A água de cocção drenada foi para estufa de secagem a $105^{\circ} \mathrm{C}$ por $12 \mathrm{~h}$. O cálculo foi realizado da seguinte maneira: $\mathrm{AA}=[($ peso arroz cozido/peso do arroz cru)*100] e PS = [(peso do resíduo de evaporação/peso arroz cru)*100]. $\mathrm{O}$ VE foi medido pelo método de deslocamento de volume, com a adição de $1 \mathrm{~g}$ de arroz cru em um 
volume conhecido de água destilada e observando a mudança de volume total. Após o cozimento do arroz, o volume deslocado também foi medido. O cálculo foi realizado da seguinte forma: VE = [(volume deslocado pelo arroz cozido/volume deslocado pelo arroz cru)*100].

\section{Análises no arroz cozido}

Para a cocção do arroz pesou-se $3 \mathrm{~g}$ de arroz em placa de Petri (60 mm), adicionou-se 6 $\mathrm{mL}$ de água destilada e cozinhou-se por 20 min em vapor de água. Após o cozimento, as amostras ficaram em repouso por $5 \mathrm{~min}$ antes de seguir para a avaliação de textura e digestibilidade de amido.

A textura do arroz cozido foi avaliada pelos parâmetros dureza e pegajosidade em texturômetro TA.XT Plus Texture Analyzer (Stable Micro Systems) utilizando célula de carga de $50 \mathrm{~kg}$. Três grãos de arroz foram colocados equidistantes na plataforma Heavy Duty (HDP/90) e comprimidos com o probe cilíndrico P35 $(35 \mathrm{~mm})$. A velocidade de pré-teste foi de $10 \mathrm{~mm} \mathrm{~s}^{-1}$ e a de teste foi de $5 \mathrm{~mm} \mathrm{~s}^{-1}$, com compressão de $90 \%$. Foram realizadas 6 leituras por amostra. A máxima força de compressão foi utilizada como indicadora da dureza do arroz, enquanto que a adesão do probe após a compressão foi usada como indicadora da pegajosidade.

A digestibilidade in vitro do amido foi realizada no arroz cozido de acordo com o método de Englyst et al. (1992), com adaptações. Em tubo de ensaio (50 mL) foi pesado $1 \mathrm{~g}$ de arroz cozido fresco e adicionado $10 \mathrm{~mL}$ de tampão acetato $0,1 \mathrm{M}$ e pH 5,2 contendo $4 \mathrm{mM}$ de $\mathrm{CaCl}_{2}$. A amostra foi homogeneizada em homogeneizador Superohm por $10 \mathrm{~s}$ a velocidade 5 . O conteúdo do tubo foi transferido para um béquer $(100 \mathrm{~mL})$ e o tubo foi lavado 2 vezes com $5 \mathrm{~mL}$ do mesmo tampão acetato. Após 5 min em banho térmico a $37{ }^{\circ} \mathrm{C}$, adicionou-se $5 \mathrm{~mL}$ de mistura enzimática. Alíquotas de $0,5 \mathrm{~mL}$ foram retiradas nos intervalos de 0,20 e 120 min e colocadas em tubo de centrífuga $(15 \mathrm{~mL})$ contendo $4 \mathrm{~mL}$ de etanol absoluto. Os tubos foram centrifugados por $10 \mathrm{~min}$ a $1500 \mathrm{~g}$. A amostra remanescente foi fervida por $30 \mathrm{~min}$, adicionada de $10 \mathrm{~mL}$ de $\mathrm{KOH} 7 \mathrm{M}$ e agitada a $25^{\circ} \mathrm{C}$ por $30 \mathrm{~min}$, seguida de tratamento com amiloglucosidase (A7095, Sigma-Aldrich). A quantidade de glicose liberada a cada período de hidrólise foi quantificada com o reagente glicose oxidase-peroxidase (Glicose PAP Liquiform, Labtest Diagnóstica). Os teores das diferentes frações foram obtidos com base na definição de Englyst et al. (1992): ARD, glicose liberada de 0 a 20 minutos; ALD, de 20 a 120 minutos; e AR, não digerido após 120 minutos.

Para a mistura enzimática foi pesado $1,5 \mathrm{~g}$ de pancreatina (P1750, Sigma-Aldrich), adicionado $10 \mathrm{~mL}$ de água destilada e deixado $10 \mathrm{~min}$ sob agitação em agitador magnético (TE-085, Tecnal). Após a agitação, procedeu-se a centrifugação por $10 \mathrm{~min}$ a $1500 \mathrm{~g} ; 8 \mathrm{~mL}$ do sobrenadante foi retirado e misturado com 0,4 mL de amiloglucosidase (A7095, Sigma-Aldrich) e $5 \mathrm{mg}$ de invertase (I4504, Sigma-Aldrich). Esta solução foi preparada imediatamente antes de ser utilizada. 


\section{Delineamento experimental e análise estatística}

O delineamento experimental foi o inteiramente casualizado, com três repetições. Os resultados foram submetidos ao Teste $\mathrm{t}(\mathrm{p}<0,05)$ para comparação de médias utilizando-se o sistema estatístico ASSISTAT versão 7.6 beta.

\section{Resultados e Discussão}

\section{Análises no arroz cru}

A composição centesimal do arroz de ambas as cultivares pode ser visualizada na Tabela 1. O teor de umidade do arroz, tanto da cultivar IAC 202 quanto da IRGA 417, atende a legislação, pois está abaixo do limite máximo de $14 \%$ preconizado pela mesma para conservação do cereal (BRASIL, 2009).

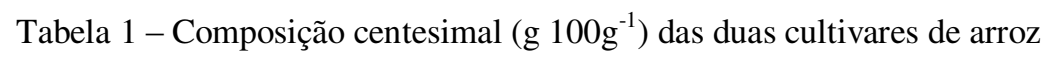

\begin{tabular}{ccccccc}
\hline Arroz & Umidade & Proteínas & Lipídeos & Cinzas & FA & CHO \\
\hline IAC 202 & $9,7 \pm 0,21 \mathrm{a}$ & $6,6 \pm 0,23 \mathrm{~b}$ & $0,2 \pm 0,01 \mathrm{~b}$ & $0,2 \pm 0,04 \mathrm{a}$ & $1,6 \pm 0,45 \mathrm{a}$ & 81,7 \\
IRGA 417 & $10,0 \pm 0,19 \mathrm{a}$ & $7,5 \pm 0,13 \mathrm{a}$ & $0,3 \pm 0,04 \mathrm{a}$ & $0,3 \pm 0,06 \mathrm{a}$ & $1,6 \pm 0,34 \mathrm{a}$ & 80,3 \\
\hline
\end{tabular}

Nota: Médias de três repetições \pm desvio padrão. Médias seguidas pela mesma letra na coluna não diferem entre si pelo Teste $\mathrm{t}(\mathrm{p}<0,05)$.

Legenda: $\mathrm{FA}=$ fibra Alimentar; $\mathrm{CHO}=$ carboidratos.

Os teores de lipídeos de ambas as cultivares são similares aos teores encontrados na literatura, que são de 0,12 a 1,22\%, já os teores de cinzas e fibra alimentar estão abaixo dos valores da literatura, que são de 0,34 a 0,50\% e de 1,60 a 1,69\%, respectivamente (CHÁVEZ-MURILLO et al., 2011; UNICAMP, 2006; USP, 2011; ZANÃO et al., 2009). Para a cv. IAC 202 o teor de proteínas foi inferior ao citado por outros trabalhos $(6,73-11,00 \%)$, já para a cv. IRGA 417, o valor foi similar (CHÁVEZ-MURILLO et al., 2011; UNICAMP, 2006; USP, 2011; ZANÃO et al., 2009). Essas diferenças podem decorrer de diversos fatores, mas principalmente da diferença entre cultivares de arroz, ano safra, adubação e condições edafo-climáticas.

$\mathrm{O}$ conteúdo de aminoácidos presentes nas proteínas determina a sua qualidade. $\mathrm{O}$ arroz apresenta uma das maiores concentrações de lisina entre os cereais, o que faz com que tenha o balanço de aminoácidos mais completo (WALTER et al., 2008). A fração lipídica do arroz, apesar dos baixos teores, é composta por quantidade significativa de ácidos graxos insaturados, que são importantes para a saúde e, por não serem sintetizados pelo organismo humano, devem ser supridos pela alimentação (NAVES, 2007; WALTER et al., 2008).

Observa-se pelos valores de cor (Tabela 2) que a cv. IAC 202 diferiu da IRGA 417 em todos os parâmetros, com maior luminosidade (L), cor mais vívida (croma) e tonalidade (ângulo hue) menos próxima do amarelo $\left(90^{\circ}\right)$. 
Tabela 2 - Cor, teor de amilose aparente (\%) e valor de espalhamento alcalino das duas cultivares de arroz

\begin{tabular}{cccccc}
\hline Arroz & L & Croma & Ângulo hue & TAA & VEA \\
\hline IAC 202 & $73,5 \pm 0,35 \mathrm{a}$ & $9,5 \pm 0,20 \mathrm{a}$ & $95,4 \pm 0,26 \mathrm{a}$ & $26,4 \pm 0,35 \mathrm{~b}$ & $4,0 \pm 0,30 \mathrm{~b}$ \\
IRGA 417 & $68,4 \pm 1,40 \mathrm{~b}$ & $8,4 \pm 0,31 \mathrm{~b}$ & $93,6 \pm 0,64 \mathrm{~b}$ & $27,8 \pm 0,31 \mathrm{a}$ & $7,0 \pm 0,00 \mathrm{a}$ \\
\hline
\end{tabular}

Nota: Médias de três repetições \pm desvio padrão. Médias seguidas pela mesma letra na coluna não diferem entre si pelo Teste $t(p<0,05)$. Legenda: $\mathrm{L}=$ luminosidade; TAA = teor de amilose aparente; VEA = valor de espalhamento alcalino.

O teor de amilose aparente (Tabela 2) foi menor para a cv. IAC 202, apesar da diferença de apenas 1,4 pontos percentuais entre as cultivares. Este teor de amilose classifica-os como arroz de alto teor de amilose (MARTíNEZ e CUEVAS, 1989). Diferenças no teor de amilose podem decorrer de genótipo, ambiente e interação entre estes fatores (SOAVE et al., 1995).

O conteúdo de amilose presente no arroz é de extrema importância para as características finais do produto cozido. Arroz com baixo teor de amilose é mais macio, pegajoso, coesivo, úmido, enquanto o arroz com alto teor de amilose é mais firme, solto e enxuto (JAYAMANI et al., 2007; PERDON et al., 1999), o que faz com que a preferência do consumidor brasileiro seja por grãos com maior teor de amilose.

O valor de espalhamento alcalino (VEA) é uma forma indireta para estimar a temperatura de gelatinização (TG) pelo grau de dispersão e clarificação dos grãos de arroz em solução alcalina (MARTÍNEZ e CUEVAS, 1989). O arroz IAC 202 apresentou VEA (Tabela 2) de 4,0; o que indica que possui TG intermediária, já o arroz IRGA 417 apresentou valor 7,0, portanto, TG baixa.

As propriedades de pasta do arroz podem ser visualizadas na Tabela 3 e o viscoamilograma na Figura 1. Não houve diferença na temperatura de pasta entre as cultivares. Como pode se observar pela Figura 1, ambas as cultivares começaram a ganhar viscosidade ao mesmo tempo, ou seja, na mesma temperatura. O tempo para atingir o pico de viscosidade foi maior para a cv. IRGA 417, uma vez que esta apresentou viscosidade maior.

Tabela 3 - Propriedades de pasta das duas cultivares de arroz

\begin{tabular}{ccccccc}
\hline \multirow{2}{*}{ Arroz } & \multirow{2}{*}{$\begin{array}{c}\text { Temperatura de } \\
\text { pasta }\left({ }^{\circ} \mathbf{C}\right)\end{array}$} & \multirow{2}{*}{ Tempo de pico } & \multicolumn{4}{c}{ Viscosidade (RVU) } \\
\cline { 4 - 7 } & & (min) & Pico & Quebra & Final & Retrogradação \\
\hline IAC 202 & $88,3 \pm 1,24 \mathrm{a}$ & $5,8 \pm 0,20 \mathrm{~b}$ & $126,9 \pm 3,22 \mathrm{~b}$ & $39,3 \pm 3,69 \mathrm{a}$ & $175,1 \pm 6,87 \mathrm{~b}$ & $87,6 \pm 7,59 \mathrm{~b}$ \\
IRGA 417 & $90,3 \pm 0,50 \mathrm{a}$ & $6,6 \pm 0,14 \mathrm{a}$ & $186,3 \pm 2,16 \mathrm{a}$ & $13,2 \pm 2,64 \mathrm{~b}$ & $284,6 \pm 7,15 \mathrm{a}$ & $111,5 \pm 11,76 \mathrm{a}$ \\
\hline
\end{tabular}

Nota: Médias de três repetições \pm desvio padrão. Médias seguidas pela mesma letra na coluna não diferem entre si pelo Teste $\mathrm{t}(\mathrm{p}<0,05$ ). 


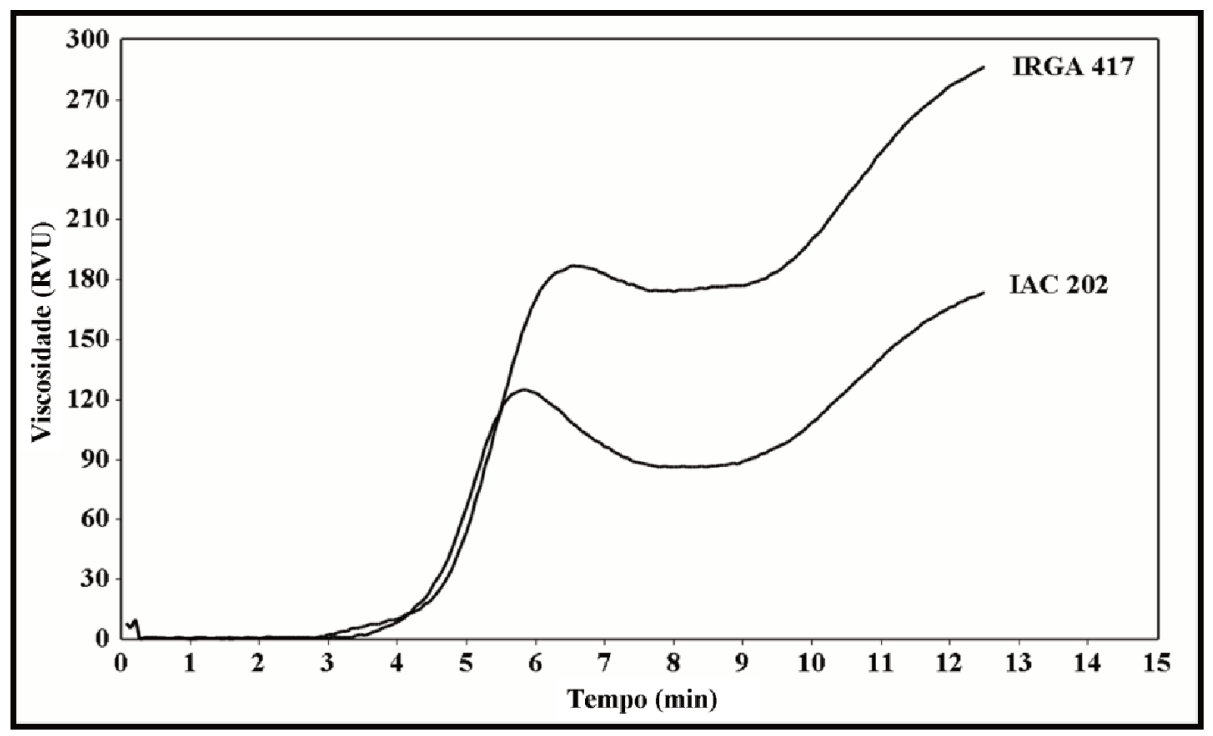

Figura 1 - Viscoamilograma obtido pelo RVA das duas cultivares de arroz

O arroz IRGA 417 apresentou maior viscosidade (pico, final e retrogradação) e menor cizalhamento a quente (quebra). Valor de viscosidade superior significa maior capacidade de expansão dos grânulos de amido durante o processo de gelatinização e pode estar relacionado ao maior teor de amilose deste arroz (CHÁVEZ-MURILLO et al., 2011), já a resistência dos grânulos à ruptura durante a agitação sob aquecimento pode ser devido ao maior teor de proteínas e lipídeos do arroz IRGA 417. As proteínas do arroz revestem os grânulos de amido, formando uma barreira espessa que regula sua expansão e cizalhamento a quente (LIKITWATTANASADE e HONGSPRABHAS , 2010). Os lipídeos impedem a hidratação dos grânulos, pois se combinam com moléculas de amilose curtas e regiões lineares da amilopectina, contribuindo também para o menor cizalhamento a quente dos grânulos de amido (CHÁVEZ-MURILLO et al., 2011; FITZGERALD et al., 2003). Além disso, o comprimento das cadeias de amilopectina interfere na viscosidade, Han e Hamaker (2001), observaram correlação negativa das cadeias longas da amilpectina com a viscosidade de quebra obtida em RVA e correlação positiva das cadeias curtas.

\section{Análises de cocção}

As propriedades de cocção do arroz das duas cultivares podem ser visualizadas na Tabela 4. O tempo mínimo de cocção não se alterou entre as cultivares, apesar da cv. IRGA 417 ter apresentado maior VEA, ou seja, menor temperatura de gelatinização. Como esta cultivar apresentou maior teor de proteínas e lipídeos que dificultam a absorção de água e intumescimento dos grânulos de amido, como discutido anteriormente, pode ser que o tempo necessário para o seu cozimento tenha sido aumentado. Além disso, defeitos dos grãos como fissuras e núcleo gessado, e características estruturais como tamanho e forma das células do endosperma influenciam o tempo de cocção do arroz (VIDAL et al., 2007). 
Tabela 4 - Propriedades de cocção das duas cultivares de arroz

\begin{tabular}{ccccc}
\hline Arroz & TMC (min) & AA (\%) & VE (\%) & PS (\%) \\
\hline IAC 202 & $17,7 \pm 0,58$ a & $459,7 \pm 12,90 \mathrm{a}$ & $529,3 \pm 7,51 \mathrm{a}$ & $4,9 \pm 0,67 \mathrm{a}$ \\
IRGA 417 & $17,0 \pm 0,00 \mathrm{a}$ & $384,7 \pm 9,02 \mathrm{~b}$ & $495,3 \pm 8,08 \mathrm{~b}$ & $2,3 \pm 0,51 \mathrm{~b}$ \\
\hline
\end{tabular}

Nota: Médias de três repetições \pm desvio padrão. Médias seguidas pela mesma letra na coluna não diferem entre si pelo Teste $\mathrm{t}(\mathrm{p}<0,05)$.

Legenda: TMC = tempo mínimo de cocção; $\mathrm{AA}=$ absorção de água; $\mathrm{VE}=$ volume de expansão; $\mathrm{PS}=$ perda de sólidos.

O arroz cv. IAC 202 apresentou maior absorção de água, volume de expansão e perda de sólidos na água de cocção. A maior PS pode estar relacionada com a maior AA e VE, pois com os grãos de arroz mais expandidos, a lixiviação de moléculas para o meio aumenta. Esse comportamento pode estar relacionado ao maior teor de amilopectina, pois esta macromlécula é a principal responsável pela expansão dos grânulos de amido durante a gelatinzação (SONG e JANE, 2000).

\section{Análises no arroz cozido}

No arroz cozido foi analisada a textura e a digestibilidade do amido (Tabela 5). $\mathrm{O}$ arroz IRGA 417 apresentou maior dureza que o IAC 202, provavelmente pela menor AA e VE. O teor de amilose também está relacionado com este parâmetro de textura, quanto maior o teor de amilose maior a dureza (CHAVEZ-MURILLO et al. 2011; YU et al. 2009). A cv. IRGA 417 que apresentou maior teor de amilose aparente, também apresentou maior dureza. No entanto, esta relação é indireta, pois a composição influencia a propriedade funcional de expansão e consequentemente a textura final do arroz cozido. No entanto, as diferenças encontradas na textura do arroz são atribuídas não apenas ao teor de amilose, mas também às diferentes estruturas da amilopectina, cadeias curtas, por exemplo, estão relacionadas à textura macia, enquanto cadeias longas estão relacionadas à textura mais firme do arroz (CHAMPAGNE et al., 1999; GARCIA et al., 2011; ONG e BLANSHARD, 1995).

Tabela 5 - Textura (kg) e digestibilidade in vitro do amido (\% base seca) das duas cultivares de arroz

\begin{tabular}{cccccc}
\hline Arroz & Dureza & Pegajosidade & ARD & ALD & AR \\
\hline IAC 202 & $3,9 \pm 0,16 \mathrm{~b}$ & $-1,1 \pm 0,04 \mathrm{~b}$ & $74,0 \pm 1,91 \mathrm{~b}$ & $1,6 \pm 0,31 \mathrm{a}$ & $5,7 \pm 0,32 \mathrm{~b}$ \\
IRGA 417 & $4,4 \pm 0,07 \mathrm{a}$ & $-1,0 \pm 0,02 \mathrm{a}$ & $80,4 \pm 0,44 \mathrm{a}$ & $0,7 \pm 0,12 \mathrm{~b}$ & $7,3 \pm 0,47 \mathrm{a}$ \\
\hline
\end{tabular}

Nota: Médias de três repetições \pm desvio padrão. Médias seguidas pela mesma letra na coluna não diferem entre si pelo Teste $t$ ( $\mathrm{p}<0,05$ ).

Legenda: $\mathrm{ARD}=$ amido rapidamente digerível; $\mathrm{ALD}=$ amido lentamente digerível; $\mathrm{AR}=$ amido resistente.

A pegajosidade é representada por valores negativos, pois é determinada no sentido contrário da dureza no texturômetro, portanto, quanto mais negativo maior a pegajosidade. Dessa forma, o IAC 202 foi mais pegajoso, o que está de acordo com a menor dureza e maior AA e VE. A pegajosidade do arroz cozido pode ser afetada por ligações entre a oryzenina, maior componente da 
proteína do arroz, e o amido, pois no cozimento ambos são parcialmente destruídos, o que permite interações por adsorção reversível entre eles (RAMESH et al., 2000; TULYATHAN e LEEHARATANALUK, 2007). Esta proteína também pode influenciar a dureza do arroz cozido devido às pontes dissulfeto que restringem a expansão do amido durante a gelatinização (LIKITWATTANASADE e HONGSPRABHAS, 2010; ZHOU et al., 2003, 2010).

O teor de ARD foi menor na cv. IAC 202, assim como o teor de AR. De modo geral, o teor de ALD foi baixo para ambas cultivares, mas para a IRGA 417 foi ainda menor. O teor de AR correlacionou-se positivamente com o teor de amilose aparente. Chung et al. (2010) observaram teores de AR entre 0,2 e 1,1\% e de ALD entre 0,3 a 6,2\%, em cultivares canadenses de arroz com teor de amilose variando de 3,7 a 23,7\%, concluindo que maiores teores de amilose estão relacionados a menor digestibilidade do amido (mais ALD e AR). Já Chavez-Murillo et al. (2011), não encontraram correlação da digestibilidade com o teor de amilose em cultivares mexicanas de arroz com valores de 71-76\% pata ARD, 4-9\% para ALD e 5-8 para AR. Estes autores, concluíram que existem outros fatores intrínsecos e extrínsecos que influenciam na digestibilidade do amido. Benmoussa et al. (2007) observaram correlação negativa das cadeias longas e intermediárias da amilopectina com o teor de ARD e positiva das cadeias curtas.

\title{
4 Conclusão
}

O arroz da cultivar IAC 202 apresentou maior AA, VE, PS, pegajosidade e ALD. O arroz da cultivar IRGA 417 apresentou maior teor de proteínas, lipídeos, amilose aparente, viscosidade em RVA, dureza, ARD e AR. O arroz IRGA 417 apresentou características de textura mais apreciada pelos brasileiros, com grão cozido mais firme e menos pegajoso. Além disso, apresentou vantagem nutricional sobre o IAC 202 pelo maior teor de proteínas e AR.

\begin{abstract}
The objective of this study was to characterize physicochemical, functional and nutritional of two rice Brazilian cultivars. The rice cultivar IAC 202 had higher gelatinization temperature, water absorption, expansion volume, loss of solids, stickiness and slowly digestible starch. The rice cultivar IRGA 417 showed a higher content of protein, lipids, apparent amylose, RVA viscosity, hardness, rapidly digestible starch and resistant starch. Rice IRGA 417 showed texture features most appreciated by Brazilians with cooked grain firmer and less sticky. Furthermore, it presented nutritional advantage on the IAC 202 by higher protein content and resistant starch.
\end{abstract}

Key-words: Oryza sativa, composition, cooking properties, starch digestibility, texture.

\section{Referências}

AMERICAN ASSOCIATION OF CEREAL CHEMISTS - AACC. Approved methods of American Association of Cereal Chemists. Method 61-02. 10th ed. St. Paul, 2000.

ASSOCIATION OF OFFICIAL ANALYTICAL CHEMISTRY - AOAC. Official methods of analysis of the Association of Official Analytical Chemistry. 18th ed. Arlington, 2006. 1141 p. 
BASSINELlO, P. Z.; ROCHA, M. S.; COBUCCI, R. M. A. Avaliação de diferentes métodos de cocção de arroz de terras altas para teste sensorial. Santo Antônio de Goiás: Embrapa Arroz e Feijão, 2004.

BELLO-PÉREZ, L.A.; MONTEALVO, M.G.M.; ACEVEDO, E.A. Almidón: definición, estructura y propriedades. In: LAJOLO, F.M.; MENEZES, E.W. Carbohidratos em alimentos regionales iberoamericano. São Paulo: Edusp, 2006. p. 17-46.

BENMOUSSA, M.; MOLDENHAUER, K. A. K.; HAMAKER, B. R. Rice amylopectin fine structure variability affects starch digestion properties. Journal of Agricultural and Food Chemistry, v. 55, n. 4, p. 1475-1479, 2007. DOI: $10.1021 /$ jf062349x.

BRASIL. Leis, decretos, etc. Instrução Normativa $n^{\circ}$ 6, de 19 de fevereiro de 2009. Regulamento Técnico do Arroz. Diário Oficial da União, Brasília, 17 de fevereiro de 2009.

CASTRO, E. M.; VIEIRA, N. R. A.; RABELO, R. R.; SILVA, S. A. Qualidade de grãos em arroz. Santo Antônio de Goiás: Embrapa Arroz e Feijão, 1999. 30 p.

CHAMPAGNE, E. T.; BETT, K. L.; VINYARD, B. T.; MCCLUNG, A. M.; BARTON, F. E.; MOLDENHAUER, K., LINSCOMBE, S.; MCKENZIE, K. Correlation between cooked rice texture and Rapid Visco Analyses measurements. Cereal Chemistry, v. 76, n. 5, p. 764-771, 1999. http://dx.doi.org/10.1094/CCHEM.1999.76.5.764.

CHÁVEZ-MURILlO, C. E.; WANG, Y. J.; QUINTERO-GUTIERREZ, A. G.; BELLO-PEREZ, L. A. Physicochemical, Textural, and Nutritional Characterization of Mexican Rice Cultivars. Cereal Chemistry, v. 88, n. 3, p. 245-252, 2011. http://dx.doi.org/10.1094/CCHEM-10-10-0146.

CHUNG, H. J.; LIU, Q.; HOOVER, R. Impact of annealing and heat-moisture treatment on rapidly digestible, slowly digestible and resistant starch levels in native and gelatinized corn, pea and lentil starches. Carbohydrate Polymers, v. 75, n. 3, p. 436-447, 2009. http://dx.doi.org/10.1016/j.carbpol.2008.08.006.

CHUNG, H. J.; LIU, Q.; WANG, R. L.; YIN, Y. L.; LI, A. K. Physicochemical Properties and In Vitro Starch Digestibility of Cooked Rice from Commercially Available Cultivars in Canada. Cereal Chemistry, v. 87, n. 4, p. 297 304, 2010. http://dx.doi.org/10.1094/cchem-87-4-0297.

COMPANHIA NACIONAL DE ABASTECIMENTO. Acompanhamento de safra brasileira: grãos, sétimo levantamento, abril 2012. Brasília: CONAB, 2012. 37 p.

CUI, L.; PAN, Z. L.; YUE, T. L.; ATUNGULU, G. G.; BERRIOS, J. Effect of ultrasonic treatment of brown rice at different temperatures on cooking properties and quality. Cereal Chemistry, v. 87, n. 5, p. 403-408, 2010. http://dx.doi.org/10.1094/CCHEM-02-10-0034.

ENGLYST, H. N.; KINGMAN, S. M.; CUMMINGS, J. H. Classification and measurement of nutritionally important starch fractions. European Journal of Clinical Nutrition, v. 46, p. S33-S50, 1992.

FERREIRA, M.C.; PINHEIRO, B.S.; SOUZA, I.S.F.; MORAIS, O.P. Qualidade do arroz no Brasil: evolução e padronização. Santo Antônio de Goiás : Embrapa Arroz e Feijão, 2005. 61 p.

FITZGERALD, M. A.; MARTIN, M.; WARD, R. M.; PARK, W. D.; SHEAD, H. J. Viscosity of rice flour: A rheological and biological study. Journal of Agricultural and Food Chemistry, v. 51, p. 2295-2299, 2003. DOI: $10.1021 / \mathrm{jf0} 20574 \mathrm{i}$

GARCIA, D. M.; BASSINELlO, P. Z.; ASCHERI, D. R. P.; ASCHERI, J. L. R.; TROVO, J. B.; COBUCCI, R. D. A. Cooking quality of upland and lowland rice characterized by different methods. Ciência e Tecnologia de Alimentos, v. 31, n. 2, p. 341-348, 2011. http://dx.doi.org/10.1590/S0101-20612011000200010.

HAN, X. Z.; HAMAKER, B. R. Amylopectin fine structure and rice starch paste breakdown. Journal of Cereal Science, v. 34, n. 3, p. 279-284, 2001. http://dx.doi.org/ 10.1006/jcrs.2001.0374.

INSTITUTO BRASILEIRO DE GEOGRAFIA E ESTATÍSTICA. Pesquisa de orçamentos familiares 2008-2009: análise do consumo alimentar pessoal no Brasil. Rio de Janeiro: IBGE, 2011. 150 p. 
JAYAMANI, P.; NEGRAO, S.; BRITES, C.; OLIVEIRA, M. M. Potential of waxy gene microsatellite and singlenucleotide polymorphisms to develop japonica varieties with desired amylose levels in rice (Oryza sativa L.). Journal of Cereal Science, v. 46, n. 2, p. 178-186, 2007. http://dx.doi.org/10.1016/j.jcs.2007.03.003.

LEHMANN, U.; ROBIN, F. Slowly digestible starch - its structure and health implications: a review. Trends in Food Science \& Technology, v. 18, n. 7, p. 346-355, 2007. http://dx.doi.org/10.1016/j.tifs.2007.02.009.

LIKITWATTANASADE, T.; HONGSPRABHAS, P. Effect of storage proteins on pasting properties and microstructure of Thai rice. Food Research International, v. 43, n. 5, p. 1402-1409, 2010. http://dx.doi.org/10.1016/j.foodres.2010.04.011.

LITTLE, R. R.; HILDER, G. B.; DAWSON, E. H. Differential effect of dilute alkali on 25 varieties of milled white rice. Cereal Chemistry, v. 35, n. 2, p. 111-126, 1958.

MARTÍNEZ, C.; CUEVAS, F. Evaluación de la calidad culinaria y molinera del arroz. 3. Cali: CIAT, 1989.73.

NAVES, M. M. V. Características químicas e nutricionais do arroz. Boletim do Centro de Pesquisa de Processamento de Alimentos, v. 25, n. 1, p. 51-60, 2007.

ONG, M. H.; BLANSHARD, J. M. V. Texture determinants in cooked, parboiled rice .1. Rice starch amylose and the fine-structure of amylopectin. Journal of Cereal Science, v. 21, n. 3, p. 251-260, 1995. http://dx.doi.org/10.1006/jcrs.1995.0028.

PERDON, A. A.; SIEBENMORGEN, T. J.; BUESCHER, R. W.; GBUR, E. E. Starch retrogradation and texture of cooked milled rice during storage. Journal of Food Science, v. 64, n. 5, p. 828-832, 1999. http://dx.doi.org/10.1111/j.1365-2621.1999.tb15921.x.

RAMESH, M.; BHATTACHARYA, K. R.; MITCHELL, J. R. Developments in understanding the basis of cooked-rice texture. Critical Reviews in Food Science and Nutrition, v. 40, n. 6, p. 449-460, 2000. http://dx.doi.org/10.1080/10408690091189220.

SAJILATA, M. G.; SINGHAL, R. S.; KULKARNI, P. R. Resistant starch - A review. Comprehensive Reviews in Food Science and Food Safety, v. 5, n. 1, p. 1-17, 2006. DOI: 10.1111/j.1541-4337.2006.tb00076.x.

SOAVE, D.; BASTOS, C. R.; AZZINI, L. E.; ZULLO, M. A. T. Teor de amilose em genótipos de arroz. Bragantia, v. 54, p. 11-15, 1995.

SONG, Y.; JANE, J. Characterization of barley starches of waxy, normal and high amylose varieties. Carbohydrate Polymers, v. 41, n. 4, p. 365-377, 2000. http://dx.doi.org/10.1016/S0144-8617(99)00098-3.

TULYATHAN, V.; LEEHARATANALUK, B. Changes in quality of rice (Oryza sativa L.) cv. Khao Dawk Mali 105 during storage. Journal of Food Biochemistry, v. 31, n. 3, p. 415-425, 2007. http://dx.doi.org/10.1111/j.17454514.2007.00125.x.

UNIVERSIDADE DE CAMPINAS. Tabela brasileira de composição de alimentos (TACO). Campinas: NEPAUNICAMP, 2006. 113 p.

UNIVERSIDADE DE SÃO PAULO. Tabela brasileira de composição de alimentos (TBCA-USP 5.0). Disponível em: < http://www.fcf.usp.br/tabela/resultado.asp?IDLetter=A\&IDNumber=208>. Acesso em: 11 out. 2011.

VIDAL, V.; PONS, B.; BRUNNSCHWEILER, J.; HANDSCHIN, S.; ROUAU, X.; MESTRES, C. Cooking Behavior of Rice in Relation to Kernel Physicochemical and Structural Properties. Journal of Agricultural and Food Chemistry, v. 55, p. 336-346, 2007. http://dx.doi.org/10.1021/jf061945o.

WALTER, M.; MARCHEZAN, E.; AVILA, L. A. Arroz: composição e características nutricionais. Ciência Rural, v. 38, n. 4, p. 1184-1192, 2008. http://dx.doi.org/10.1590/S0103-84782008000400049.

YU, S. F.; MA, Y.; SUN, D. W. Impact of amylose content on starch retrogradation and texture of cooked milled rice during storage. Journal of Cereal Science, v. 50, n. 2, p. 139-144, 2009. http://dx.doi.org/10.1016/j.jcs.2009.04.003. 
ZANÃO, C. F. P.; CANNIATTI-BRAZACA, S. G.; SARMENTO, S. B. S.; ARTHUR, V. Efeito da irradiação gama nas características físico-químicas e sensoriais do arroz (Oryza sativa L.) e no desenvolvimento de Sitophilus oryzae L. Ciência e Tecnologia de Alimentos, v. 29, p. 46-55, 2009. http://dx.doi.org/10.1590/S0101-20612009000100008.

ZAVAREZE, E. R.; HALAL, S. L. M.; PEREIRA, J. M.; RADÜNZ, A. L.; ElIAS, M. C.; DIAS, A. R. G. Caracterização química e rendimento de extração de amido de arroz com diferentes teores de amilose. Brazilian Journal of Food Technology, v. II SSA, p. 24-30, 2009.

ZHOU, Z. K.; ROBARDS, K.; HELLIWELL, S.; BLANCHARD, C. Effect of rice storage on pasting properties of rice flour. Food Research International, v. 36, n. 6, p. 625-634, 2003. http://dx.doi.org/10.1016/S0963-9969(03)00013-9.

ZHOU, Z. K.; ROBARDS, K.; HELLIWELL, S.; BLANCHARD, C. Effect of storage temperature on rice thermal properties. Food Research International, v. $43, \quad$ n. $\quad 3, \quad$ p. $\quad 709-715, \quad 2010$. http://dx.doi.org/10.1016/j.foodres.2009.11.002.

Submetido em 23 abr. 2013, Aceito para publicação em 20 dez. 2013. 